\title{
The Heavens in September, 1922
}

\author{
What the Astronomers Will Do in Pursuit of Einstein's 13/4 Seconds of Arc
}

\author{
By Professor Henry Norris Russell, Ph.D.
}

THE principal astronomical interest of the present 1 month undoubtedly attaches to the total eclipse of the sun upon the 20 th. This is a notable one, for the moon is actually at perigee during the eclipse, so that the point of the shadow reaches unusually far beyond the earth, and the dark spot which it produces upon the earth's surface is exceptionally large, reaching a diameter of 140 miles. Moreover, it falls in the equatorial regions, so that the earth's rotation carries the observer rapidly in the direction in which the shadow is moving, and hence prolongs the time of it passage. The combined influence raises the duration of totality to the unusual maximum of six minutesless a couple of seconds. The opportunities for observations of all kinds are therefore. unusually favorable-excent for one circumstance, which remains to be mentioned; by far the greatest part of the eclipse track lies in the open ocean.

At its very beginning it passes for a few hundred miles over Africa, south of Somaliland; but the sun will be so low for observers here that it would be useless to attempt scientific observations. Then begins a vast sweep of the Indian Ocean, interrupted along the eclipse track only by some coral islands of the Maldive group, southwest of India, and the isolated Christmas Island, south of Java. Land comes at last, with the Australian coast; but on the shore, and for a thousand miles or more inland, it is a most forbidding desert. In the eastern part of Australia, near the borders of Queensland and New South Wales, a more practicable country is reached, with railroads and towns; but here again the sun is low, for the end of the track (out in the Pacific) is not far off.

The practicable eclipse stations, where the sun will be high and the weather promising, appear to be confined to the islands in the Indian Ocean and the deser stations in Australia.

It is doubtful whether much effort would be made to occupy such inconvenient places, if it were not that this will be the last chance for a number of years to settle the question of the bending of light rays by the sun's grayitation, as predicted by Einstein. The observations of 1919 though fully enough to satisfy those who are familiar with all the intricacies of photographic measurement, showed certain small discrepancies, probably arising from defects in the apparatus. The earlier results worked up at the Lick Observatory, though also favorable to the relativity effect, were not quite decisive. One new set of observations, secured with instruments specially designed for the problem, and under good conditions, should settle the question beyond cavil. At the present eclipse the sun is in a region rather poor in stars; but the long duration of totality compensates for this, and will make it possible to secure satisfactory photographs-if only the weather permits.

Where the Eclipse Will be Photographed

Several expeditions, therefore, are under way. A German party, including Professor Einstein himself, will be in the Maldives; an English party at Christmas Island; and our most experienced American observer of eclipses, Professor Campbell, on the northwest coast of Australia; while Australian astronomers plan to work in the interior of that continent, and some smaller parties will be at the stations already named. The problem of transportation, for some of the adventurers, will be no simple one. The Greenwich observers (who are already on Christmas Island, and plan to do an important piece of photometric work while awaiting the eclipse) had to remain in the offing, tossed about in a very small steamer, for more than a week before the sea was smooth enough to permit a landing. And the voyagers to Australia are likely to have more remarkable tales to tell.

The Lick Observatory party, after crossing the Pacific by steamer and the Australian continent by, rail, wil travel more than a thousand miles on a gunboatgenerously detailed for that purpose by the Australian

Government-and land on Ninety-Mile Beach, where the only way of getting ashore is in surf-boats, and the tide has a range of 20 feet. Water, and possibly a few sheep for food, are procurable at a ranch near the shore. Everything else will have to come thousands of miles.

It may be permissible to mention one detail, which Dr. Campbell told the writer and which illustrates the thoroughness of his preparations. The upsetting of a single boat in the surf might lead to the loss of essential parts of the instruments. Hence, among the equipment ordered in Australia will be a suitable number of stout, water-tight barrels, which will be firmly lashed to each heavy package. Should the boat capsize the barrels will serve to float the cargo ashore, case by case, and it can be recovered when the ebb-tide leaves it stranded.

Needless to say, the precautions taken on the technical side will be fully as complete. The description of these will come when Professor Campbell makes his report; but it may be mentioned that the comparison plates of the same stars when the sun is in another

ing a little to the west, it reaches Fomalhaut, and the southern constellation of the Crane. The eastern side of the square points southward to the brightest star in Cetus. The rest of this large constellation lies to the left, and can be picked out with the aid of the map. From the northeastern corner of the great square a line of conspicuous stars runs through Andromeda and Perseus, whose brightest star, Capella, is low in the northeast. Aries is well up in the east, and Taurus rising. In the opposite quarter we find Cygnus and Lyra, very high, and Hercules and Corona below. Farther to the left is Aquila, above the setting Sagittarius. Aquarius and Capricornus occupy a dull region in the south.

\section{The Planets}

Mercury is an evening star all through September, and is farthest away from the sun in the sky on the 20th. His elongation is then unusually great-261/2 degrees-but he is more than 10 degrees south of the sun and is therefore not very conspicuous, setting at $6: 45$ P. M. (standard time, as always). Venus, too, is an evening star, and reaches her greatest elongation on the 15 th-46 degrees 24 minutes from the sun. She is still farther south, and sets at $7: 45$ P. M., so that she is less conspicuous than she was earlier in the year.

Mars is in Sagittarius, receding from the earth and growing fainter. He crosses the meridian shortly after sunset, and remains in sight until 11 o'clock.

Jupiter and Saturn are evening stars, setting at $8: 10$ P. M. and 7 P. M., respectively, at the beginning of the month. Not long afterward they are lost in the twilight. Mercury is in conjunction with Saturn on the 8th, and with Jupiter on the $21 \mathrm{st}$; but in both cases the planets will be very low in the west.

Uranus comes to opposition on the 4 th, and is just visible to the naked eye. At that time he is in $22 \mathrm{~h} 33 \mathrm{~m} 20 \mathrm{~s}$ R. A., and 7 degrees 58 seconds south declination, and is moving a little less than 9 seconds westward and 1 minute southward per day. This places him 11/4 degrees due east of the fourth magnitude star Lambda Aquarii, which may itself be found about 3 degrees east of the line joining Zeta and Delta Aquarii (shown on the map), and a little nearer the latter. The planet is barely visible to the naked eye, but is conspicuous in a field glass. By making a sketch map and watching for his motion, he may be certainly identified.

Neptune is a morning star, rising about $4: 30 \mathrm{~A}$. M. in the middle of the month.

The moon is full at $3 \mathrm{~A}$. M. on the $6 \mathrm{th}$, in her last quarter at $5 \mathrm{~A}$. M. on the 14 th, new at $11 \mathrm{P}$. M. on the 20 th, and in her first quarter at $6 \mathrm{P}$. M. on the 27 th. She NIGHT SKY: SEPTEMBER AND OCTOBER

part of the sky will be taken in the Island of Tahiti, since it would be impossible to wait for months in the desert to take them there. Very complete checks and controls upon the permanence of the instrumental adjustments will also be made. The scale of the whole expedition is very well illustrated by the fact that some of its members will return across the Pacific and others via Europe-since to go around the world is almost the shortest way home!

One of the Australian parties plans a still bolder trip, to an almost unknown desert region, which can be reached only by a journey of some weeks with a camel train. The chances that good weather will bless these desert parties are very favorable; and we may hope that, when the photographs have been measured and the results worked out, the great observational test of the Theory of Relativity will have been completed, once for all.

\section{The Heavens}

In picking out the constellations, we may begin with the great square of Pegasus, which is conspicuous high in the southeast. Its western edge points northward, past Cassiopeia and Cepheus, to the Pole-star, and to the Great Bear below it. Carried southward, and trend- is nearest the earth on the 20th, and furthest away on the 7 th. During the month she passes by Uranus on the 6th, Neptune on the 18th, Saturn on the 21st, Jupiter and Mercury on the 22nd, Venus on the 24th, and Mars on the 28th.

It may be added that at $3: 10 \mathrm{P}$. M. on the $23 \mathrm{rd}$ the sun crosses the celestial equator, southward bound, and "autumn commences."

\section{The Radium Star Map}

CSERS of star maps find more or less difficulty in the fact that one must look at the stars in the dark, and that in the dark one cannot see a map. It is by no means convenient to pass back and forth between light and darkness, and the use of a flashlight is not much better. A Chicago inventor is putting on the market a radium map, in which the stars of the first four magnitudes, together with the lines showing the constellation groupings, are marked with radium so as to shine in the dark. This map is four feet long and one foot wide, mounted on cardboard for folding; it carries the circumpolar stars on one section, and those that appear to rise and set on another. Dates are given when certain regions of the sky are due north at 9 P. M. 